\title{
AVALIAÇÃO DE MUDAS DE MARACUJAZEIRO EM FUNÇÃO DO SUBSTRATO E DO TIPO DE BANDEJA
}

\author{
R.P. de OLIVEIRA; W.B. SCIVITTARO \\ Centro de Energia Nuclear na Agricultura/USP - C.P. 96 - CEP: 13400-900 - Piracicaba,SP. \\ L.A.B.C. de VASCONCELLOS \\ Departamento de Horticultura - ESALQ/USP - C.P. 9 - CEP: 13418-900-Piracicaba,SP.
}

\begin{abstract}
RESUMO: A utilização de bandejas de isopor na produção de mudas de hortaliças e frutiferas vem aumentando em nosso pais, devido as vantagens que esse método apresenta: economia de substrato e de área de viveiro, menor custo no controle de pragas e doenças, produção de mudas de alta qualidade e alto indice de pegamento após o transplante. No caso do maracujazeiro (Passiflora edulis var. flavicarpa), o transplante de mudas e uma prática bastante utilizada para sua propagação. A ocorrencia de traumatismos na raiz durante esta fase é significativa, influindo negativamente no desenvolvimento posterior das mudas. 0 presente trabalho objetivou avaliar a produção de mudas de maracuja em bandejas de isopor, comparando a eficiência de quatro substratos diferentes e dois tipos de bandejas na germinação e desenvolvimento das mudas. Conclui-se que o método de produção de mudas de maracujazeiro em bandejas é eficiente, resultando em mudas de alta qualidade, com elevada porcentagem de pegamento. Verificou-se também que na bandeja de 72 células e nos substratos Plantmax e substrato III (areia: vermiculita: esterco; 1:1:1. suplementado com $10 \mathrm{Kg} / \mathrm{m}^{3}$ de superfosfato simples, $6 \mathrm{Kg} / \mathrm{m}^{3}$ de cloreto de potassio, $2 \mathrm{Kg} / \mathrm{m}^{3}$ de uréia e $8 \mathrm{Kg} / \mathrm{m}^{3}$ de calcário houve maior porcentagem de germinaçẫo e adequado desenvolvimento das mudas.

Descritores: maracujá, Passiflora edulis var. flavicarpa, propagação.
\end{abstract}

\section{EVALUATION OF PASSIFLORA SEEDLINGS AS A FUNCTION OF SUBSTRATE AND TRAY TYPE}

SUMMARY: This paper describes the use of two types of styrofoam trays and four different substrates. The efficiency of different substrates and tray types in passionflora (Passiflora edulis var. flavicarpa) seed germination and seedling growth were analysed. The results indicated that both tray types tested are adequate for passionflora germination and seedling growth. Nevertheless the 72 cell tray type had a statistically better performance than the 128 cell tray type. Substrate III (sand; vermiculite; dung; 1:1:1, supplemented with $10 \mathrm{Kg} / \mathrm{m}^{3}$ simple superphosphate, $6 \mathrm{Kg} / \mathrm{m}^{3}$ potassium chloride, $2 \mathrm{Kg} / \mathrm{m}^{3}$ urea and $8 \mathrm{Kg} / \mathrm{m}^{3}$ lime) and substrate Plantmax were used in the cells. Both substrates had a superior performance in relation to substrates number I and II.

Key Words: passionflower, Passiflora edulis var. flavicarpa, propagation.

\section{INTRODUÇÃO}

O maracujazeiro encontra condições favoráveis ao seu desenvolvimento em regiões tropicais e subtropicais. Devido à industrialização de seus frutos e ao bom preço do suco tem-se verificado aumento em sua produção no Brasil (SUZUKI, 1987). Sua propagação pode ser feita por diferentes processos: sexuada, pelo emprego de sementes, e assexuada, pela propagação vegetativa empregando-se a estaquia ou a enxertia (STEINBERG, 1988). A semeadura pode ser feita diretamente no campo, em recipientes individuais ou em bandejas. Segundo MANICA (1981) a propagação em recipientes individuais pode ser feita por meio de vasos, bolsas de polietileno, laminados de madeira ou torrão paulista. O mesmo autor cita que os recipientes devem ser preenchidos com uma mistura composta de areia, matéria orgânica bem curtida e terra em partes iguais, sendo a mistura fumigada.

A propagação do maracujazeiro por bandejas é uma técnica de introdução recente. As bandejas são geralmente constituídas de isopor, sendo possível a sua reutilização. Além disso, permitem economia de espaço e de substrato a ser utilizado. O principal componente do substrato utilizado para propagação em bandejas é a vermiculita, que pode ser misturada a areia, esterco, solo, xaxim, esfagno e outros (MINAMI, 1982). Visando minimizar gastos com mão de obra e erros na formulação das misturas, atualmente, 
estão sendo lançados no mercado substratos prontos com formulações adequadas para o desenvolvimento normal de mudas. Um exemplo desses substratos é o PLANTMAX, produto estéril elaborado a base de vermiculita expandida $\mathrm{e}$ material orgânico, contendo macro e micronutrientes necessários ao desenvolvimento inicial das mudas.

Este trabalho teve como objetivo comparar a porcentagem de germinação e o desenvolvimento de plântulas de maracujá em substratos preparados a base de vermiculita e no Plantmax, usando bandejas de 72 e 128 divisões.

\section{MATERIAIS E MÉTODOS}

O trabalho foi conduzido em casa de vegetação do Departamento de Horticultura da Escola Superior de Agricultura "Luiz de Queiroz" em Piracicaba. A temperatura da casa de vegetação apresentou uma média mínima de $20^{\circ} \mathrm{C}$ e uma média máxima de $40^{\circ} \mathrm{C}$ durante a realização do experimento.

O experimento foi conduzido em bandejas de isopor de 72 e 128 divisões, que foram preenchidas com os seguintes substratos: Plantmax; substrato 1, composto por uma mistura de areia, vermiculita e esterco em partes iguais, incorporando-se $2.5 \mathrm{Kg} / \mathrm{m}^{3}$ de superfosfato simples, $1.5 \mathrm{Kg} / \mathrm{m}^{3}$ de cloreto de potássio, 2.0 $\mathrm{Kg} / \mathrm{m}^{3}$ de calcário e $0.5 \mathrm{Kg} / \mathrm{m}^{3}$ de uréia; substrato, Il composto do mesmo material do substrato I, porém incorporando-se o dobro das doses dos fertilizantes utilizados; e substrato III, composto pelo mesmo material do substrato I, porém incorporando-se $o$ quadruplo das doses dos fertilizantes utilizados no substrato I.

O delineamento estatístico utilizado foi de blocos ao acaso. Utilizaram-se quatro blocos, cada um contendo 2 bandejas de 72 divisões e 2 bandejas de 128 divisões. Cada bandeja foi dividida ao meio para receber dois substratos distintos. Desta forma, cada bloco possuiu os dois tipos de bandejas e cada tipo de bandeja os quatro substratos propostos.

Utilizou-se o maracujá amarelo (Passiflora edulis var. flavicarpa) sendo as sementes obtidas segundo as recomendações de RUGGIERO (1987). A semeadura foi feita em 05/01/88, colocando-se três sementes por divisão das bandejas. Aos $\mathbf{3 0}$ dias após a semeadura foi feito o desbaste, deixando-se uma planta por divisão das bandejas.
Em relação às avaliações, foi feita uma contagem das divisões com plântulas emergentes a cada três dias após o início da germinação. A partir do vigésimo dia da semeadura, iniciou-se a coleta semanal de 4 plântulas de cada tratamento por bloco.

Mediram-se, então, a altura das plantas e o comprimento das raízes. Essas plântulas foram lavadas em água corrente, colocadas em sacos de papel etiquetados e transportadas para secagem em estufa. Posteriormente mediram-se o peso da matéria seca da raiz e o peso da matéria seca total (raiz + parte aérea) das plântulas. Foram realizadas quatro coletas semanais visando acompanhar o desenvolvimento das mudas nos substratos e bandejas utilizadas.

Aos 42 dias da germinação fez-se o transplante de 8 plantas de cada tratamento, visando observar o pegamento e postcrior desenvolvimento das mudas no campo. Procurouse, também, avaliar a coloração das plantas nos diferentes substratos.

\section{RESULTADOS E DISCUSSÕES}

Nas bandejas de 72 e 128 células obtevese uma elevada porcentagem de germinação das sementes de maracujá, respectivamente, de $81 \%$ e $75 \%$ (TABELA 1). A germinação ocorreu no período entre o oitavo ao vigésimo dia após a semeadura. Este dado revela uma germinação precoce nas bandejas, pois em germinador de areia ocorre de 15 a 20 dias após a semeadura (RUGGIERO, 1988) e em canteiros após 20 a 30 dias (MEDINA et al., 1980).

$\mathrm{Na}$ bandeja de 72 células obteve-se a maior porcentagem de germinação, devido, provavelmente, ao maior volume de substrato envolvendo a semente em cada célula, o que proporciona melhores condições à germinação.

Em relação aos substratos pesquisados, o Plantmax apresentou a maior porcentagem média de germinação, porém não diferiu estatisticamente dos substratos II e III a partir do vigésimo dia após a semeadura (TABELA 2). Nesta TABELA, podese verificar que os 4 substratos estudados apresentaram alta porcentagem média de germinação, não apresentando problemas de toxicidade dos componentes dos substratos.

Pelas TABELAS 3 e 4 verifica-se que na bandeja 72 ocorreu o melhor desenvolvimento das plantas em todas as fases de crescimento das mudas, independente do substrato utilizado. 
TABELA 1 - Percentagem média de germinação de sementes de maracujá (Passiflora edulis var. flavicarpa) semeadas em dois tipos de bandejas e avaliada a cada três dias após a semeadura. Piracicaba, 1990.

\begin{tabular}{cccccc} 
& \multicolumn{5}{c}{ Germinação \% } \\
\cline { 2 - 6 } Bandeja & 8 & 11 & 14 & 17 & 20 \\
\cline { 2 - 6 } & $20,0 \mathrm{a}$ & $29,9 \mathrm{a}$ & $58,1 \mathrm{a}$ & $79,3 \mathrm{a}$ & $81,0 \mathrm{a}$ \\
\hline 72 & $15,7 \mathrm{~b}$ & $22,5 \mathrm{~b}$ & $47,3 \mathrm{~b}$ & $73,8 \mathrm{~b}$ & $75,0 \mathrm{~b}$ \\
\hline 128 & 2,5 & 4,5 & 7,4 & 5,2 & 5,1 \\
DMS (Tukey 5\%) & 19,3 & 23,6 & 18,9 & 9,2 & 8,8 \\
\hline \hline
\end{tabular}

(*) Dados transformados para ARC sen $\sqrt{ } \times / 100$

TABELA 2 - Percentagem média de germinação de sementes de maracujá (Passiflora edulis var. flavicarpa) semeadas em quatro substratos e avaliada a cada três dias após a semeadura. Piracicaba, 1990.

\begin{tabular}{cccccc}
\hline & \multicolumn{5}{c}{ Germinação \% } \\
\cline { 2 - 6 } & \multicolumn{5}{c}{ Dias após a semeadura } \\
\cline { 2 - 6 } Substratos & 8 & 11 & 14 & 17 & 20 \\
\hline Plantmax & $19,3 \mathrm{a}$ & $29,5 \mathrm{a}$ & $58,8 \mathrm{a}$ & $79,8 \mathrm{a}$ & $82,6 \mathrm{a}$ \\
Substrato I & $21,4 \mathrm{a}$ & $32,7 \mathrm{a}$ & $53,1 \mathrm{a}$ & $71,0 \mathrm{a}$ & $71,1 \mathrm{~b}$ \\
Substrato II & $18,3 \mathrm{a}$ & $26,2 \mathrm{a}$ & $53,3 \mathrm{a}$ & $78,7 \mathrm{a}$ & $79,2 \mathrm{ab}$ \\
Substrato III & $12,2 \mathrm{~b}$ & $16,2 \mathrm{~b}$ & $45,6 \mathrm{a}$ & $76,6 \mathrm{a}$ & $79,3 \mathrm{ab}$ \\
\hline DMS (Tukey 5\%) & 4,8 & 8,6 & 13,9 & 9,9 & 9,6 \\
C.V. (\%) & 19,3 & 23,6 & 18,9 & 9,2 & 8,8 \\
\hline \hline
\end{tabular}

$\left(^{*}\right)$ Dados transformados para ARC sen $\sqrt{ } x / 100$

Este fato provavelmente se deve ao maior volume de substrato que está envolvendo a planta neste tipo de bandeja, propiciando condições mais satisfatórias ao seu desenvolvimento.

Com relação ao desenvolvimento das mudas nos diferentes substratos pesquisados, verificou-se que de uma maneira geral, o Plantmax e o substrato III apresentavam os melhores resultados com relação às variáveis estudadas (TABELAS 5 e 6). Durante a fase de crescimento das mudas verificou-se que aquelas que se encontravam no substrato Plantmax apresentavam uma coloração verde mais intensa, propiciando mudas de melhor qualidade. 
TABELA 3 - Comprimento médio da raíz, altura das plantas, peso da matéria seca da raíz e peso da matéria seca total das plantas de maracujá (Passiflora edulis var. flavicarpa) verificados na terceira e quarta semanas após a semeadura em dois tipos de bandejas. Piracicaba, 1990.

\begin{tabular}{lccccccccc}
\hline \hline & \multicolumn{10}{c}{ S E M A N A S } \\
\cline { 2 - 10 } Bandejas & \multicolumn{1}{c}{3} & \multicolumn{7}{c}{4} \\
\cline { 2 - 10 } & C.Raíz & A.Total & P.Raíz & P.Total & C.Raíz & A.Total & P.Raíz & P.Total \\
& $(\mathrm{cm})$ & $(\mathrm{cm})$ & $(\mathrm{mg})$ & $(\mathrm{mg})$ & $(\mathrm{cm})$ & $(\mathrm{cm})$ & $(\mathrm{mg})$ & $(\mathrm{mg})$ \\
\hline 72 & $5,5 \mathrm{a}$ & $10,1 \mathrm{a}$ & $5,9 \mathrm{a}$ & $32,8 \mathrm{a}$ & $9,5 \mathrm{a}$ & $15,7 \mathrm{a}$ & $18,2 \mathrm{a}$ & $93,9 \mathrm{a}$ \\
128 & $4,8 \mathrm{~b}$ & $9,4 \mathrm{~b}$ & $4,7 \mathrm{~b}$ & $27,6 \mathrm{~b}$ & $7,7 \mathrm{~b}$ & $14,2 \mathrm{~b}$ & $12,9 \mathrm{~b}$ & $73,9 \mathrm{~b}$ \\
\hline DMS (Tukey 5\%) & 0,5 & 0,7 & 1,0 & 4,1 & 0,8 & 0,8 & 1,6 & 10,7 \\
C.V. (\%) & 12,8 & 10,0 & 26,5 & 18,3 & 12,9 & 7,7 & 14,2 & 17,4 \\
\hline \hline
\end{tabular}

TABELA 4 - Comprimento médio da raíz, altura das plantas, peso da matéria seca da raíz e peso da matéria seca total das plantas de maracujá (Passiflora edulis var. flavicarpa) verificados nas quinta e sexta semanas após a semeadura em dois tipos de bandejas. Piracicaba, 1990.

\begin{tabular}{cccccccccc}
\hline & \multicolumn{10}{c}{ S E M A N A S } \\
\cline { 2 - 10 } Bandejas & \multicolumn{10}{c}{5} & \multicolumn{7}{c}{6} \\
\cline { 2 - 10 } & C.Raíz & A.Total & P.Raíz & P.Total & C.Raíz & A.Total & P.Raíz & P.Total \\
& $(\mathrm{cm})$ & $(\mathrm{cm})$ & $(\mathrm{mg})$ & $(\mathrm{mg})$ & $(\mathrm{cm})$ & $(\mathrm{cm})$ & $(\mathrm{mg})$ & $(\mathrm{mg})$ \\
\hline 72 & $5,9 \mathrm{a}$ & $14,9 \mathrm{a}$ & $20,5 \mathrm{a}$ & $155,8 \mathrm{a}$ & $5,2 \mathrm{a}$ & $16,70 \mathrm{a}$ & $37,3 \mathrm{a}$ & $264,5 \mathrm{a}$ \\
128 & $4,8 \mathrm{~b}$ & $13,3 \mathrm{~b}$ & $12,7 \mathrm{~b}$ & $101,3 \mathrm{~b}$ & $4,3 \mathrm{~b}$ & $15,2 \mathrm{~b}$ & $20,5 \mathrm{~b}$ & $156,9 \mathrm{~b}$ \\
\hline DMS (Tukey 5\%) & 0,7 & 1,2 & 3,5 & 17,2 & 0,7 & 0,9 & 6,6 & 33,2 \\
C.V. (\%) & 18,1 & 11,7 & 28,7 & 18,2 & 19,4 & 8,1 & 31,1 & 21,4 \\
\hline \hline
\end{tabular}

O fato do substrato III apresentar melhores resultados quanto ao desenvolvimento das mudas, em relação aos substratos I e II, demonstra a resposta das plântulas de maracujazeiro a adubação. Segundo MEDINA et al. (1980) pouco se conhece sobre as exigências de macro e micronutrientes na formação de mudas de maracujazeiro e, portanto, este resultado merece ser melhor estudado.

Nas TABELAS 3, 4, 5 e 6 pode-se verificar que a partir da quarta semana, praticamente, não houve aumento do comprimento das raízes das plantas em todos os tratamentos. Isto se deve a pequena profundidade das bandejas de isopor, porém este fato não afetou o crescimento das mudas, pois as raízes passaram a crescer lateralmente, o que se comprova pelo aumento do peso da matéria seca total das raizes.

Com relação a porcentagem de pegamento após o transplante, esta foi de $100 \%$ para todos os tratamentos, demonstrando a eficiência do método de produção de mudas por bandejas. 
TABELA 5 - Comprimento médio da raíz, altura das plantas, peso da matéria seca da raíz e peso da matéria seca total das plantas de maracujá (Passiflora edulis var. flavicarpa) verificados na terceira e quarta semanas após a semeadura em quatro substratos. Piracicaba, 1990.

\begin{tabular}{lccccccccc}
\hline & \multicolumn{7}{c}{ Semanas ap6́s a semeadura } \\
\cline { 2 - 9 } & \multicolumn{7}{c}{3} & \multicolumn{7}{c}{4} \\
\cline { 2 - 9 } Substratos & C.Raiz & A.Total & P.Raíz & P.Total & C.Raíz & A.Total & P.Raíz & P.Total \\
& (cm) & (cm) & (mg) & (mg) & (cm) & (cm) & (mg) & (mg) \\
\hline Plantmax & $5,5 \mathrm{a}$ & $10,1 \mathrm{a}$ & $5,6 \mathrm{ab}$ & $29,8 \mathrm{a}$ & $9,2 \mathrm{a}$ & $15,4 \mathrm{a}$ & $15,7 \mathrm{a}$ & $97,5 \mathrm{a}$ \\
Substrato I & $5,4 \mathrm{ab}$ & $10,2 \mathrm{a}$ & $6,2 \mathrm{a}$ & $33,1 \mathrm{a}$ & $9,0 \mathrm{a}$ & $15,2 \mathrm{a}$ & $16,0 \mathrm{a}$ & $73,2 \mathrm{~b}$ \\
Substrato II & $5,3 \mathrm{ab}$ & $9,8 \mathrm{a}$ & $5,6 \mathrm{ab}$ & $29,9 \mathrm{a}$ & $8,4 \mathrm{a}$ & $14,8 \mathrm{a}$ & $16,3 \mathrm{a}$ & $80,4 \mathrm{ab}$ \\
Substrato III & $4,5 \mathrm{~b}$ & $9,0 \mathrm{a}$ & $3,8 \mathrm{~b}$ & $28,2 \mathrm{a}$ & $8,0 \mathrm{a}$ & $14,3 \mathrm{a}$ & $14,4 \mathrm{a}$ & $84,6 \mathrm{ab}$ \\
\hline DMS (Tukey 5\%) & 0,9 & 1,4 & 2,0 & 7,7 & 1,5 & 1,6 & 3,1 & 20,4 \\
C.V. (\%) & 12,8 & 10,0 & 26,5 & 18,3 & 12,9 & 7,7 & 14,2 & 17,4 \\
\hline \hline
\end{tabular}

TABELA 6 - Comprimento médio da raíz, altura das plantas, peso da matéria seca da raíz e peso da matéria seca total das plantas de maracujá (Passiflora edulis var. flavicarpa) verificados na quinta e sexta semanas após a semeadura em quatro substratos. Piracicaba, 1990.

\begin{tabular}{lccccccccc}
\hline & \multicolumn{8}{c}{ Semanas ap6́s a semeadura } \\
\cline { 2 - 9 } Substratos & \multicolumn{7}{c}{5} \\
\cline { 2 - 9 } & C.Raíz & A.Total & P.Raíz & P.Total & C.Raíz & A.Total & P.Raíz & P.Total \\
& (cm) & (cm) & (mg) & (mg) & (cm) & (cm) & (mg) & (mg) \\
\hline Plantmax & $5,9 \mathrm{a}$ & $16,5 \mathrm{a}$ & $17,5 \mathrm{ab}$ & $157,5 \mathrm{a}$ & $4,5 \mathrm{a}$ & $17,8 \mathrm{a}$ & $30,9 \mathrm{a}$ & $271,9 \mathrm{a}$ \\
Substrato I & $5,0 \mathrm{a}$ & $11,3 \mathrm{c}$ & $11,9 \mathrm{~b}$ & $86,3 \mathrm{~b}$ & $5,3 \mathrm{a}$ & $13,1 \mathrm{~b}$ & $22,5 \mathrm{a}$ & $138,8 \mathrm{c}$ \\
Substrato II & $5,6 \mathrm{a}$ & $13,4 \mathrm{bc}$ & $19,1 \mathrm{a}$ & $114,1 \mathrm{~b}$ & $4,7 \mathrm{a}$ & $14,5 \mathrm{~b}$ & $28,4 \mathrm{a}$ & $186,9 \mathrm{bc}$ \\
Substrato III & $5,0 \mathrm{a}$ & $15,2 \mathrm{ab}$ & $17,8 \mathrm{ab}$ & $156,3 \mathrm{a}$ & $4,4 \mathrm{a}$ & $18,5 \mathrm{a}$ & $33,8 \mathrm{a}$ & $245,3 \mathrm{ab}$ \\
\hline DMS (Tukey 5\%) & 1,4 & 2,3 & 6,6 & 32,7 & 1,3 & 1,8 & 12,6 & 62,9 \\
C.V. (\%) & 18,1 & 11,7 & 28,7 & 18,2 & 19,4 & 8,1 & 31,1 & 21,4 \\
\hline \hline
\end{tabular}

\section{CONCLUSÕES}

1- A germinação de sementes de maracujá em bandejas ocorre predominantemente entre a segunda e a terceira semanas nos substratos Plantmax e nos substratos compostos por uma mistura de areia, esterco e vermiculita em partes iguais incorporando-se diferentes combinaçōes de fertilizantes;

2- A bandeja 72 apresentou a maior porcentagem de germinação das sementes de maracujá; 
3- Os substratos pesquisados apresentaram alta porcentagem de germinação, sendo o Plantmax e os substratos II e III os melhores;

4- A bandeja 72 apresentou os melhores resultados com relação ao desenvolvimento de mudas, independentemente do substrato utilizado;

5- Os melhores substratos são o Plantmax e o substrato III com relação ao desenvolvimento de mudas de maracujá;

6- O método de produção de mudas de maracujazeiro em bandejas $\varepsilon$ bastante eficiente resultando em alta porcentagem de pegamento das mudas transplantadas.

\section{REFERÊNCIAS BIBLIOGRAFICAS}

MANICA, I. Fruticultura tropical: maracuja. Sŭo Paulo, Ed. Agronômica Ceres. 1981. 160p.

MEDINA, J.C.; GARCLA, J.L.M.; LARA, J.C.C.; TOCCHINI, R.P.; HASHIZUME, T.; MORETTI, V.A.; CANTO, W.L. Maracujá da cultura ao processamento e comercializaçato. Campinas, ITAL, 1980. 207p. (Frutas Tropicais, 9).
MINAMI, $K$. Vermiculita. In: VII SEMANA DE CIÉNCIA E TECNOLOGLA AGROPECUÁRIA DE JABOTICABAL, 7., Jaboticabal, 1982.5p.

RUGGIERO, C. Implantação da cultura e propagação . In: Maracuja. Ribeirão Preto: Legis Suma, 1988. p.40-57.

STEINBERG, F. Maracujá: Guia prático para um manejo equilibrado. São Paulo, Nobel, 1988. 64p.

SUZUKJ, O.Y. Considerações econômicas brasileiras. In: RUGGIERO, C. ed. Maracujá. Ribeirăo Preto: Legis Suma, 1987. p.8-20.
Trabalho enviado para publicação em 08.07 .92 Trabalho aceito para publicação em 29.04 .93 